\title{
Social media in emergency management: exploring Twitter use by emergency responders in the UK
}

\section{Sophie Parsons* and Mark Weal}

Web and Internet Science Group,

University of Southampton,

Southampton, UK

Email: sp13g10@southampton.ac.uk

${ }^{*}$ Corresponding author

\section{Nathaniel O'Grady}

Humanitarian Conflict Response Institute,

Ellen Wilkinson Building,

University of Manchester,

M13 9PL, UK

Email: nathaniel.ogrady@manchester.ac.uk

\section{Peter M. Atkinson}

Department of Lancaster Environment Centre,

University of Lancaster,

Lancaster, UK

Email:pma@lancaster.ac.uk

\begin{abstract}
Emergency management practices are being reshaped by social media. Emergency responders are embracing social media to enhance communications during an emergency. The integration of social media into UK emergency management is ambigious, and it is uncertain as to whether it is an effective tool. Using a mixed methods approach, this research investigates the UK emergency responders use of social media for emergency management, focusing in particular on the UK Winter Floods of 2013/14. Furthermore, the effectiveness of the UK emergency responders' social media activity is examined. This research shows that the responders perceive social media as a useful tool to effectively deliver information to the public, although they do not appear to fully exploit it in an emergency. While the responders appear to predominantly post caution and advice, the results suggest that information about structures and utilities affected by an incident is most likely to engage an audience.
\end{abstract}

Keywords: UK floods; emergency management; social media; audience engagement; mixed methods; Twitter; emergency responders; emergency communications; local resilience forums; thematic analysis. 
Reference to this paper should be made as follows: Parsons, S., Weal, M., O'Grady, N. and Atkinson, P.M. (xxxx) 'Social media in emergency management: exploring Twitter use by emergency responders in the UK', Int. J. Emergency Management, Vol. x, No. x, pp.xxx-xxx.

Biographical notes: Sophie Parsons is a doctoral researcher funded by the Web Science Doctoral Training Centre at the University of Southampton. She has received a Bachelors degree in Information Technology in Organisations and a Masters in Web Science, both at University of Southampton.

Mark Weal is an Associate Professor in the Web and Internet Science Group a the University of Southampton. He is the Director of the Centre for Doctoral Training in Web Science and is a co-director of the LifeGuide program of research, a multidisciplinary initiative that has attracted funding of well over $£ 30$ million (from MRC, EPSRC, ESRC, NIHR, EC and medical charities) for the development of online digital public health interventions.

Nathaniel O'Grady is a Lecturer in Human Geography within the Department of Geography and Environment at the University of the West of England, Bristol. His research currently examines the politics of emergency government, including topics related to the development of response protocols and the use of communication technologies.

Peter M. Atkinson is Faculty Dean at the University of Lancaster. His current research interests focus on "spatial data science", which spans a wide range of statistical and numerical techniques in both science and social science domains.

\section{Introduction}

Technological advances are changing the way that information is accessed and exchanged, with new modes of delivery and speeds of exchange, that were not possible even only a decade ago. In particular, social media has evolved from a place for posting and sharing general short messages, to a useful tool for broadcasting and disseminating breaking news and emergency communications (Vieweg et al., 2010). In times of emergency, people desire information updates about the incident, and are keen to provide information as a means to assist in the general response efforts of emergency responders (Hughes et al., 2008).

During emergencies in recent years, social media has increasingly been exploited as a tool to access and share information, express opinions and feelings, search for support and provide help to those in need, during disasters and emergencies (Terpstra et al., 2012). For example: during the Virginia Tech Shootings 2007, students used Facebook to identify who was safe and alive (Vieweg et al., 2008); Individuals local to the Red River Floods 2009 used Twitter to distribute information on flood-related matters including evacuation and sandbagging (Palen et al., 2010); and during the Japan Great Tohoku Earthquake and Tsunami 2011, individuals utilised Twitter to request assistance (Adam and Muraki, 2011). Since, emergency responders have been reportedly adopting social media for emergency management activities. During Hurricane Sandy 2012, emergency responders used social 
media to communicate with the public, predominantly distributing information about transportation services, safety instructions, and weather updates (Hughes et al., 2014). In 2013, an attack on Westgate Mall in Kenya took place. Social media became a crucial channel for communications between the Government, emergency responders and the public, primarily to provide situational awareness updates (Simon et al., 2015).

Emergency responders are encouraged to have a social media presence for communicating and exchanging knowledge in an emergency (White, 2011). It is even recommended that social media is incorporated into emergency plans and training exercises (Wood and Glik, 2013). Although best practices is still in its infancy (Siskey and Islam, 2016), and the effectiveness of social media use by emergency responders remains uncertain. Hughes et al. (2014) conducted a review of four online communication media by fire and police departments in 26 U.S. counties affected by Hurricane Sandy. Their results show a relatively low and diverse use of online media by the fire and police departments during the event. Moving forward, it is essential to better understand the use and impact of emergency responders' social media activity (Hughes et al., 2014). For example, researchers have recognised that benefits of social media go beyond emergency warning and response. Dufty and Stuart (2016) conclude that social media could play a significant role in the future of resilience-building. However, whilst the vast opportunities that social media could offer to emergency management have been discussed, it is imperative to consider the limitations of social media. For example, it cannot be assumed that all users will see every message shared, power outages can be problematic (accessing social media relies on an internet connection and devices that have a battery), and generally social media users are of a specific demographic.

Thus, the contribution of this paper, which is a part of on-going research, is to provide an initial insight into what role social media plays in emergency management, whilst also considering the problems of social media that could prohibit its successfulness as a tool for emergency management. Before we can assess the impact of the responders' social media activity, it is firstly important to uncover exactly how and why they are using it. In 2012, the UK Government commissioned the Defence Science and Technology Laboratory (DSTL) to produce a guidance document for category 1 emergency responders on how to use social media for emergency management (the document can be found at: Using Social Media in Emergencies: Smart Practices ${ }^{1}$ ). However, as found in Hughes et al. (2014), emergency responders do not always strictly follow online communication policies and protocols in times of emergency. It is impossible to assess the success of social media if we do not know what it is they are trying to achieve; do they perceive it as a mechanism to simply communicate information to a target audience, or is it they want to engage with their audience - creating and developing relationships? The latter, 'Audience Engagement', is often sought on social media to reach a larger audience and establish relationships (Briones et al., 2011). Generally, audience engagement is more than just the size of a user's follower network, it is also about the interactions between users. For example, on Twitter, audience engagement can be realised through the number of replies, likes or retweets a user receives from their followers (Zamparas et al., 2015). Measuring engagement can provide an indication of the level of interest in a user's social media activity. Thus, by examining the level of engagement between the responders and their audience on social media, we can begin to understand how many people are acknowledging the responders messages on social media, and ultimately identify possible impact of the responders' social media usage (Briones et al., 2011). However, it is important to emphasise that it would only be an indication of possible 
engagement. It is impossible to measure actual engagement, as some actions, such as the number of users that only read social media posts, cannot be measured (Phethean, 2014).

This paper will explore the UK emergency responders' (UK responders) perception and uses of social media, with a specific focus on audience engagement. Using a novel combination of methods, involving a rigorous analysis of social media data with qualitative interviews, this paper aimed to answer the following research questions (RQs):

RQ1: What role do the UK responders believe social media fulfils in Emergency Management?

RQ2: Do the UK responders try to engage with their audience on social media, and how do they engage them?

$R Q 3$ : What aspects of the UK responders' social media activity engages their audience?

As a map of the paper, it moves as follows: The next section will introduce the important aspects of UK Emergency Management, followed by a brief description of social media. Section 4 provides a summary of the event of the UK Floods 2013/14, which is used to provide context for this research, and then an overview of the mixed methods approach used (Twitter Analysis and Qualitative Interviews) follows. Sections 6 to 10 will use the findings from the studies, and the related literature, to answer the three research questions outlined above.

\section{UK emergency management}

Emergencies in the UK are defined as:

- "an event or situation that threatens serious damage to human welfare in a place in the UK; serious damage to the environment in a place in the UK, or war, or terrorism, which threatens serious damage to the security of the UK." - Civil Contingencies Act (2004).

A collection of emergency responders, in connection with central Government, are responsible for the provision of UK Emergency Management. As a requirement of Civil Contingencies Act (2004), 42 Local Resilience Forums were formed across the UK. These are multi-agency partnerships, made up of emergency responder representatives. The LRFs serve communities defined by the boundaries of Police Areas across the UK. They focus on identifying risks, planning, and preparing for a range of emergencies, with the goal of preventing or mitigating possible consequences to their local communities (Cabinet Office, 2014). Since the Civil Contingencies Act (2004), UK emergency responders have been split into two categories.

Category 1 responders are organisations at the core of emergency management. These include: The Emergency Services (Police, Fire and Ambulance), HM Coastguard, local authorities (District and County Councils), the Environment Agency, NHS bodies including Public Health England/Wales, and Port Health Authorities. Some of their roles in relation to information provision include creating and enforcing emergency plans, sharing information with other responders to enhance co-ordination, and assessing the risk of emergencies 
occurring (Cabinet Office, 2013). Ultimately, they are responsible for mitigating, controlling and minimising the effects of an emergency, by performing planned procedures such as initiating alerts, organising evacuations, and carrying out remedial actions, for example fighting fires and combating the spread of disease. In addition, the category 1 responders must also plan and prepare for the secondary impacts. For example, as an emergency unfolds, the category 1 responders must plan to handle increased interest as a consequence of the media attention and public response it is likely to receive (Cabinet Office, 2013).

Category 2 responders are private sector bodies, mostly utility companies and transport organisations, and are typically not involved in core multi-agency emergency response and recovery work. However, they can have an important role if their sector is affected during an emergency (HM Government, 2013). Category 2 responders include Gas and Electricity distributors, water and sewer undertakers, telecommunications providers, Train, Airport, and Harbour operating companies, Network Rail, Transport for London and Highways England. This research will focus on Category 1 responders only.

\section{An introduction to social media}

The World Wide Web (Web) has evolved significantly since its 'birth' in 1991. In the early years of the 21 st Century, people began to play a role in shaping the Web, forming the 'Social Web'. This new era involved the emergence of social media (Phethean, 2014). Social media is a term used to represent a group of online applications formed of user-generated content. Users may be individuals, companies, or other organisations. Ultimately, social media platforms offer opportunities to communicate and collaborate on a local, national, and global scale, facilitating a place for discussion and sharing opinions. Users can build profiles about themselves, establish connections with other users, post updates, share media, and distribute messages either publicly or privately. Some platforms are built to rely mostly on two-way reciprocation; two users must both accept one another before they can be classed as connected and are able to view each others content, whilst others only require a one-way follow where no reciprocation is required.

Twitter, a microblogging service launched in 2006, is a popular social media platform. According to Alexa.com (a Web analytic service), Twitter is second of the top 500 sites on the Web, determined by the number of sites that link to it and the average daily visitors and page views it receives (Alexa, 2017).

It is designed to enable users to post short updates, restricted to 140 characters, called 'tweets'. It offers users the opportunity to follow other users so that they can: view that user's tweets (no reciprocation is required); share each others posts, known as 'retweeting'; participate in conversations using the reply button; and express an opinion about a tweet typically to show appreciation of a tweet - by 'liking' (rebranded from 'favourite' in 2015). Each user has a 'timeline' made up of tweets posted by other users that particular user follows, and various features are available to increase the chances of a tweet being seen by other users. For example, the hashtag symbol (\#) before a particular word or phrase is used to categorise that tweet, and mentions; a tweet containing another user's username, will notify the user/s of that tweet.

Recent research shows that social media sites, particularly Twitter, are frequently used during times of emergency as a place for people to converse and gather timely, relevant information (Vieweg et al., 2010). 


\section{The UK winter floods 2013-2014}

October 2013 heralded the beginning of an unforgettable event in the UK. St Jude's Storm was the first of at least 12 storms to hit the UK during the winter months of December 2013, and January/February 2014. It is considered to be the stormiest period of weather the UK has experienced since 1969 (Rogers and Bryson, 2014). Persistently heavy rainfall and strong winds caused wide spread disruption and devastation across many southern regions. UK records for winter reached $165 \%$ of average rainfall, hurricane force winds, and record-breaking high tides in the Humber and Thames Estuaries (Met Office, 2015a; Thorne, 2014). Rivers including the Thames burst their banks, trees were brought down by high winds, and sea defences were weakened, if not destroyed (Met Office, 2015a). High water tables and the extent of soil saturation caused an increase in sink holes and triggered landslides (Thorne, 2014).

At least 10 fatalities were attributed to the event. Hundreds of people were left without power, many were forced to leave their homes, and farmers had to evacuate livestock from flooded land (Met Office, 2015a,b). According to the Met Office, around 50,000 homes experienced blackouts over the Christmas period, and between January and February 2014, the Environment Agency reported at least 6,000 properties flooded and up to 100,000 homes and businesses without power (Met Office, 2015a). Transport infrastructures were also affected, causing chaos for commuters. Railways were destroyed, roads were flooded, and airports including Gatwick were forced to terminate flights. Vulnerable areas such as the Somerset Levels were inundated with floodwaters to the extent that villages were only accessible by boat. Southern UK regions from Dorset through Hampshire, and Surrey to Sussex and Kent, were some of the most affected areas (Thorne, 2014). Figure 1, adapted from the original in Met Office (2015b), illustrates the average rainfall during the UK Winter Floods 2013/14, with an additional layer showing the region boundaries of Southern UK and the LRFs in these areas (please note the figure is not to scale).

Throughout the winter period of 2013-2014, both the public and emergency responders in the UK used social media to deliver up-to-date warnings, provide weather-related information and share media (Parsons et al., 2015; DEFRA, 2014). However, despite this investment and effort, the effectiveness of social media in this context remains uncertain. Investigating responders' social media activity is first steps towards identifying the impact of the UK responders' social media usage during the UK Floods.

\section{A mixed methods approach: using Twitter data and qualitative interviews}

This research incorporates technical approaches with techniques from human geography research and the theoretical perspectives of the social sciences. To achieve the research aims, a combination of methods was used, known as 'Mixed Methods', which integrates quantitative and qualitative methods (Creswell and Plano, 2007). A quantitative analysis of Twitter data was deemed necessary to identify how the UK responders have used a social media platform, in this case Twitter, during the UK Floods. Qualitative semistructured interviews were carried out to gain a rich understanding of the UK responders use and perceptions of social media. Generally, the related literature has focused on using quantitative studies to analyse how social media is used during emergencies. However, these data do not explain the reasons for its use, rather merely showing how the users appear 
to exploit social media. Therefore, the benefit of a Mixed Methods approach is that it can support a level of understanding that each method could not accomplish alone (Bryman, 2012).

Figure 1 Map of the average rainfall during the Winter Floods 2013/14 and the LRFs in the Southern regions of the UK (see online version for colours)
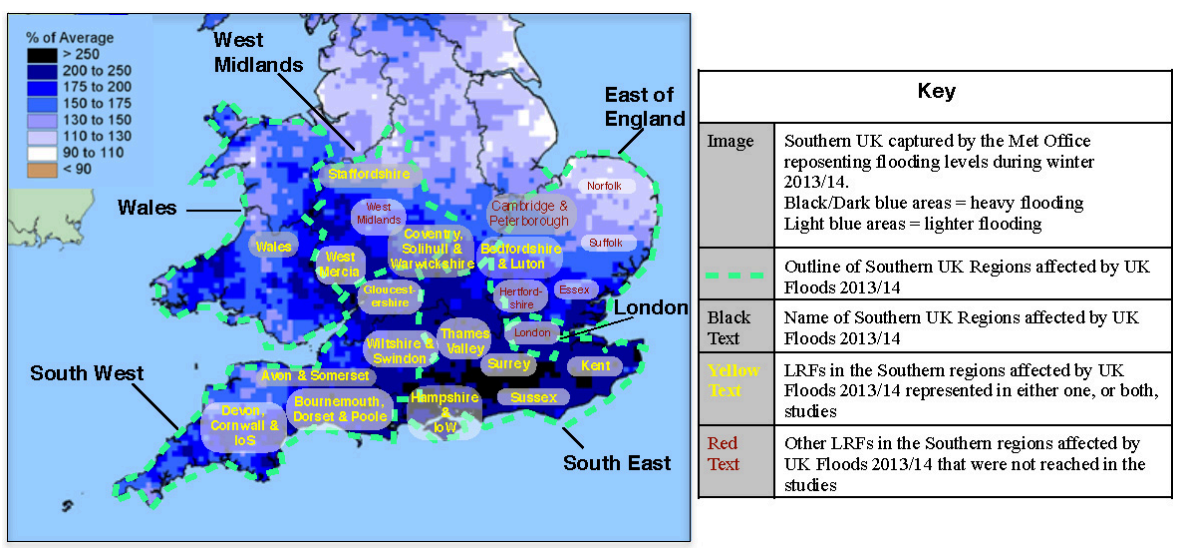

Source: Met Office (2015b)

This research focuses only on UK Category 1 emergency responders, as they are legally obligated, under the Civil Contingencies Act (2004), to carry out emergency management duties. Furthermore, the scope of this research is Southern UK as these regions were some of the most affected areas of the floods in 2013-2014 (Thorne, 2014).

\subsection{Data collection for Twitter analysis}

The Twitter analysis involved an examination of a variety of metrics, listed in Table 1, and a content analysis, categorising the tweets in accordance with a framework developed by (Olteanu et al., 2015). The authors developed a framework to outline the general types of messages posted on social media during emergencies, by conducting an extensive analysis of Twitter data related to 26 different crises. Table 2 lists the categories and provides a summary of the interpreted meaning that was used for this study. (As the analysis proceeded, it was deemed necessary to amend the category Donations and Volunteer to Donations, Volunteer and Rescue, and add an category; Flood Related Information). Before the coding process started, it was decided that Tweets could be organised into multiple categories if required.

To obtain a manageable sample size for the Twitter analysis, only the tweets of the emergency services associated with the 10 LRFs within the South West (SW) and South East (SE) Regions, were examined. The sample of tweets was retrieved using Twitter's Advanced Search; a feature that enables users, once logged into Twitter, to search through Twitter's archive of all the tweets that have been published. Users can tailor their searches by selecting filters including specific date ranges, users, location, words in the tweet content, language, and hashtags. The sample was constrained to only include tweets and retweets containing the word 'flood' in the content, and posted between the dates 1st December 2013 and 28th February 2014 inclusive. This was to ensure that the data collected were relevant to the case study, and covered the main period of the UK Floods. 
Table 1 Metrics and justifications used in the Twitter analysis

\begin{tabular}{|c|c|}
\hline Metric & Reason for Analysis \\
\hline Total Number of Tweets Posted & $\begin{array}{l}\text { According to Mei et al. (2015), this metric can be an } \\
\text { indication of how proactive the user is in using } \\
\text { Twitter, and provides an insight into their level of } \\
\text { engagement within the Twitter community; a high number } \\
\text { of tweets implies a high level of engagement }\end{array}$ \\
\hline Number of Tweets that are Retweets, & Retweets are the reposting of another user's tweet. \\
\hline Quote Retweets and Replies & $\begin{array}{l}\text { Quote Retweets are the reposting of another user's tweet } \\
\text { whilst adding original content to it. Replies are tweets that } \\
\text { are in response to another user's tweet. These metrics can } \\
\text { suggest how much a user engages in conversation with } \\
\text { their audience (Zamparas et al., 2015; Phethean et al., 2012) }\end{array}$ \\
\hline Number of Retweets & $\begin{array}{l}\text { Retweets received is the } \\
\text { number of times a tweet and Favourites received } \\
\text { is reposted by another user. Favourites received } \\
\text { is the number of times } \\
\text { a tweet is liked by another user. These can indicate } \\
\text { engagement between a user and their audience } \\
\text { (Kwak et al., 2010). They suggest a level } \\
\text { of impact that tweet has had on the audience } \\
\text { and signify a level of popularity (Zamparas et al., 2015) }\end{array}$ \\
\hline Number of Hashtags and & Hashtags are keywords or topics marked in a tweet \\
\hline URL Links (URLs) included & $\begin{array}{l}\text { by using the \# symbol. Hashtags and URLs tend to be } \\
\text { used to help find and share information } \\
\text { (Bruns and Stieglitz, 2013). They have been found } \\
\text { to correlate with the retweetability of a tweet } \\
\text { (Suh et al., 2010) }\end{array}$ \\
\hline Number of Mentions included & $\begin{array}{l}\text { Mentions are the action of tagging another user in any } \\
\text { part of the tweet by using the '@' symbol followed by their } \\
\text { username. They are believed to have the potential to } \\
\text { further the reach of a tweet. Researchers typically analyse } \\
\text { mentions to uncover user influence (Zamparas et al., 2015). } \\
\text { It is important to note that this does not include } \\
\text { a count of all the usernames, as "@ username" } \\
\text { also represents Replies }\end{array}$ \\
\hline Use of Media (photos and videos) & $\begin{array}{l}\text { Media is perceived as a method } \\
\text { of influencing interaction (Yetim et al., 2011) }\end{array}$ \\
\hline
\end{tabular}

\subsection{Data collection for semi-structured interviews}

Semi-structured interviews were chosen for this research, as the method would allow participants to offer elaborate and rich explanations for how and why they use social media. The empirical material it generates thus exceeds the brevity of survey data, offering more in-depth understanding of the motivations and techniques emergency responders possess and deploy to harness social media. Interviews took place, either Online, Face-to-Face, or by Telephone, and an Interview Guide (a short list of questions on the specific topics to be covered in the interview) was followed to ensure the primary aims of the interviews, listed below, were met: 
- $\quad$ The UK responders use of social media during an emergency.

- The UK responders motivations for using social media in Emergency Management.

- The UK responders perceptions of the use of social media for Emergency Management.

- UK responders' perceived impact of social media in Emergency Management.

To acquire interview participants, an online survey was distributed using the Snowball Sampling Technique. This involves "gathering research subjects through the identification of an initial subject who is used to provide the names of other actors. These actors may themselves open possibilities for an expanding web of contact and inquiry" (LewisBeck et al., 2004). A contact in the Hampshire LRF was the initial subject in this sampling method. Over the eight months allocated to run the survey, 14 emergency responders, from 12 LRFs in the six Southern regions of the UK, were reached. However, a limitation of this sampling method is that there is no guarantee about the representation of the sample. Table 3 gives a breakdown of the sample by sector, although organisations are kept anonymous. As illustrated previously in Figure 1, a total of 15 LRFs in the Southern Regions of the UK affected by the 2013/14 floods are represented in either one or both studies.

Table 2 Framework, adapted from (Olteanu et al., 2015), used to categorise the tweet content

\begin{tabular}{|c|c|}
\hline Information type & Summary \\
\hline Affected Individuals & $\begin{array}{l}\text { Posts specifically about individuals that have been affected } \\
\text { by the incident }\end{array}$ \\
\hline Infrastructure and Utilities & $\begin{array}{l}\text { Posts about structures such as roads, buildings, and bridges, } \\
\text { and utilities such as water and electricity supply, that have been } \\
\text { affected by the incident }\end{array}$ \\
\hline Donations, Volunteer and Rescue & $\begin{array}{l}\text { Posts related to donations of goods, services and money, } \\
\text { and volunteer actions and information }\end{array}$ \\
\hline Caution and Advice & $\begin{array}{l}\text { Posts providing warnings and informative information } \\
\text { in advance of, during, and after an incident }\end{array}$ \\
\hline Sympathy and Support & Posts offering concerns and condolences \\
\hline Flood Related Information & Information that is specifically about Flooding \\
\hline Other Useful Information & Other information that is related to the incident \\
\hline
\end{tabular}

Table 3 Sample Representation by Sector - organisations are kept anonymous

\begin{tabular}{lcc}
\hline Sector & \# of Accounts Reviewed in Twitter Analysis & \# of Interview Participants \\
\hline Fire Service & 14 & 4 \\
Police Force & 12 & 1 \\
Ambulance Service & 3 & 2 \\
Local Authority & n/a & 7 \\
\hline
\end{tabular}

For analysis purposes, each interview was manually transcribed, using the 'Intelligent Verbatim' technique; omitting mumbles, half sentences and irrelevant words such as 'ums' and 'like' without losing the meaning of the content (Salonga, n.d; SPEECHPAD, 2016). Furthermore, each transcript was returned to the participant for review, to ensure that it 
reflects what the participants intended, and reduce any misunderstandings of the data. Thematic Analysis (TA) was used to analyse the transcripts. TA is a method for "identifying, analysing, and reporting patterns (themes) within data" (Braun and Clarke, 2006). It is seen as a means to organise and describe data in rich detail, which can be achieved through a range of techniques; from word counts to line-by-line analyses (Ryan and Bernard, 2003). Generally, TA involves six steps:

1 familiarising with the data

2 devising initial codes (essentially labels or tags)

3 creating themes by grouping the initial codes

4 reviewing the themes

5 defining and naming themes, generally to form 'codebooks'

6 drawing upon the themes to form an analysis.

However, TA is not necessarily a step-by-step process; often steps are repeated and reviewed until the researcher is content.

\title{
6 Social media enhances emergency communications: the UK responders perspective
}

\author{
"we knew there was a gap, we knew we needed to communicate better -" Fire Service \\ Interviewee
}

Before an assessment of the responders' use of social media can take place, it is firstly important to uncover why and how the responders are using it. A theme that emerged from the interviews is that a key underlying motivation for integrating social media into UK Emergency Management is the responders' perception that social media will help to enhance emergency communications. Communications is a major challenge for UK emergency responders, as was explained by an interviewee:

\footnotetext{
"To give you a little bit of background: we have recently gone through what is a peer challenge, and that is, essentially, it is like an audit from a mixture of stakeholders, they come in and they assess your service on various aspects. One of those elements is communication, and that was seen as less ... as an area for development, lets put it like that ...so one of the ways that I identified to improve it ... is we use social media" - Fire Service Interviewee
}

Communication is of paramount importance in Emergency Management. Yet, it has been a common cause of failure relating to interoperability from emergencies in the UK (Pollock, 2013). A review of the Foot and Mouth Outbreak in 2001 highlighted that "information was not fully co-ordinated on a national and local scale; updates became more of a burden than a benefit; and operators of the helpline were overstretched and did not have enough up-to-date knowledge" (Anderson, 2002). Following the UK Floods 2007, the need for providing better advice and help for people to protect their families and homes, was emphasised (Pitt, 2008), and it was reported that during the London Bombings 2005, one of the biggest problems was how to communicate with the victims and their families (Strong and Eyerman, 2008). These evaluations highlight that, in terms of emergency communications, one of the most 
common challenges that the UK responders face is the ability to effectively communicate with the general citizens in a timely manner.

A trend emerged from the interviews that showed that UK responders are turning to the use of social media as a means to improve emergency communications, considering it as an option to effectively communicate with the public during emergencies. This is supported by the analysis of the responders Twitter use during the UK Floods. The results show that they made efforts to post relevant content for members of the public affected by the floods including situation updates and advice on how to handle the event; see examples below:

@ kentfirerescue: NEWS: Flood warnings issued in Kent ow.ly/rtR4s \#floodaware

@ ThamesVP: Severe flood warning in Datchet village, especially for properties in Slough Road. Please take care and do not drive through flood water.

@ SECAmbulance: If you have any health questions related to \#flooding, why not check out advice provided by the Health Protection Agency? bit.ly/NGdvmW

It is clear from the interview responses that the responders consider social media as an efficient course of action for dispersing emergency information compared with other traditional methods:

"That's just the quickest way to get it out there [...] it doesn't get filtered by the journalists" - Fire Service Interviewee

"It's faster than what ever we can put out on the radio" - Local Authority Interviewee

“During emergencies, I'm rather hoping it cuts out the middle man to be honest [...] it can get out instantly if there's something happening. If there's a flood coming down, it can go out instantly." - Police Force Interviewee

Discussion about its use for information gathering was minimal. Of those that were aware of the potential for data gathering, issues surrounding the availability of resources appear to hamper the responders' ability to exploit social media for this purpose:

"It's good to be on it for the information we get, whether in my response role I would have the time to look at it, I doubt it to be quite honest" - Police Force Interviewee

"To have that addition to the social listening side of it, not just the media warning and informing group, [...] but to bring that cell a little closer to an information intelligence cell where there was loads of social listening going on, for a regional incident that's what you really need, and that was the biggest challenge we had. We just couldn't listen to every single tweet or every single Facebook post at the time when something was happening." - Local Authority Interviewee

"So there's obviously a monitoring element to it [...] It's a full time job that is for sure, for 2 or 3 people in a situation like that." - Fire Service Interviewee

Although the UK responders may perceive social media as a useful tool for communicating directly with the public, the concern is that they may be too optimistic about who, and how many people, they can reach.

It emerged from the interviews that the majority of the responders do not know who their social media audience actually are. When prompted to describe their followers, some participants guessed, whilst others openly admitted they did not know: 
"Although quite difficult - maybe I need to give this some more thought - but we need to know who our audience are, or probably more important, who they are not." - Fire Service Interviewee

"I've never looked to check who follows [Organisation] or the [Organisation's] account” - Local Authority Interviewee

“Well, generally it's, who are our followers, it's anyone who takes an interest...I think the local communities and local responders we're pally with" - Local Authority Interviewee

"We do have a number of individuals who we are not aware of or where they are from etc. Without going into too much detail in finding that out, so I think it's members of the public" - Local Authority Interviewee

Considering the online nature of social media, understanding who the audience is, and identifying who is actually acknowledging social media posts, is a prerequisite for assessing the impact of social media for emergency communications. Only then, can the value of social media for Emergency Management be understood. Social media does not involve the entire population. In 2013, based upon the number of users in the UK on Twitter in 2013 (Curtis, 2013), and the Population of the UK in 2013 (Office for National Statistics, 2016), only $23 \%$ of the UK's population had a Twitter account, and not all accounts would have actually been active. Also, many social media users are found to be of a particular demographic. According to the (Office for National Statistics, 2013), it was observed that 16-24 year olds are the most likely demographic to use social media in the UK, and 65-74 years are the least likely. Furthermore, a significant number of social media users are not who they seem. Bots are common on social media sites (Chu et al., 2010). They deceive the public by appearing to be a real user, but are actually algorithms running automated tasks. For example, spammers use bots to push spam to numerous accounts (Chu et al., 2010). Thus, understanding who the responders followers are would provide a picture of who - if anybody - the responders are possibly reaching.

Evidently, social media is on the rise in UK Emergency Management, particularly for emergency response purposes. The UK responders believe it to be an effective mechanism for distributing emergency information to the public. However, the impact of using social media cannot be gauged effectively due to the uncertainty of who is actually following, and acknowledging, the emergency responders. Although this is the case, we can begin to identify if the responders are making effort to engage their audience, which could increase the likeliness of reaching a wider audience in an emergency situation. This is investigated in the following section.

\section{Intentions to engage vs. actions of engagement}

\footnotetext{
"It is a great way to form a relationship with people -" Local Authority Interviewee
}

Generally, social media users will choose to follow others that post relevant content to their interests. This could be a result of anything from friendships to a shared interest for breaking news or celebrity gossip (Cha et al., 2010). However, the nature of social media means that a user is not likely to see all of their followers' posts. Twitter, for example, applies a sorting algorithm, which selects the tweets to be displayed on a user's timeline, and prioritises 
the order in which they appear. The Tweets believed to be most desirable to a user will be displayed first, using machine learning techniques to compute the number of interactions that user has had with other Twitter accounts. In other words, a user is more likely to see a tweet posted by an emergency responder they follow if 1 . they have interacted with the responders' account, for example by liking, retweeting or replying to, a previous tweet, and 2. they interact with the responders' Twitter activity more than their other followers accounts. Thus, it is unlikely that each of the responders' followers will see every tweet they post. Therefore, audience engagement - capturing the followers' attention and encouraging interactions - is often sought on social media and can be exploited as a means to tackle this technical limitation (Briones et al., 2011).

It emerged from the interview responses that the responders do try to engage with their audience to achieve their main objective for using social media:

\section{"You've got to start at the bottom level and get people engaged" - Local Authority Interviewee}

"I think its more about the engagement, you want people to be engaging with you"Ambulance Service Interviewee

"We'd like to tailor the messages we put out there in order for the public to feel that they can engage with us" - Local Authority Interviewee

A variety of mechanisms for increasing audience engagement can be used on social media. Posting regular, up-to-date, and relevant content that is interesting to the public is key (Kaplan and Haenlein, 2010). Furthermore, participating in conversations, for example using Twitter's replies and mentions (Phethean, 2014); interacting with other users' messages, such as by retweeting or liking a message on Twitter (Boyd et al., 2010); and, making use of URLs, hashtags, photos and videos, which are likely to attract other users' attention (Suh et al., 2010; Yetim et al., 2011), are also considered as useful techniques to engage an audience.

The responders claimed to frequently post on various social media platforms, although it was evident during the interviews that Facebook and Twitter appeared to be their preference. Providing coverage of incidents occurring in their local areas, the responders perceive this to be the primary type of information that their audience - assumed to be the public - desire from them.

"They [Joint Emergency Control Centre] can say 'this type of incident has happened' because its just of interest to the public” - Fire Service Interviewee

"People want to know what is going on in their local area" - Fire Service Interviewee

“We'll post several times a day to each account” - Ambulance Service Interviewee

The responders also discussed using social media features to engage their audience, deeming the use of media (photos and videos) as the most important method to engage their audience:

"We do a lot using photographs and graphics" - Fire Service Interviewee

"So imaging is good, it has got to be there." - Fire Service Interviewee

"So what we've decided to do is go down the picture sharing route, as we realise this is quite a big thing at the moment" - Local Authority Interviewee 
However, the evidence collated from the Twitter Analysis, see Table 4, contradicts the responders interview responses. The number of tweets posted by the 29 organisations included in the analysis was considerably low. The responders rarely retweeted or replied to other users' tweets and their use of mentions, URLs and hashtags could be considered limited. But most interestingly, the responders' use of media was minimal.

Wukich and Mergel (2015) concluded that emergency responders knowledge of best practice and how to integrate social media appears to be limited, as they found that the responders used irrelevant hashtags in their tweets. The findings from this research suggests that the responders do appear to have an understanding of how to exploit social media features to engage their audience, but they do not appear to implement this knowledge during an emergency. It could be inferred from the results of the Twitter analysis that the UK responders use of Twitter to deliver information to the public during the UK Floods 2013-2014 was limited.

Table 4 Quantitative results from Twitter analysis

\begin{tabular}{lc}
\hline Metric Measured & Result \\
\hline No. Tweets in sample: & 800 \\
Retweets and Quote Retweets: & $12 \%$ \\
Replies: & $3 \%$ \\
Tweets with Hashtags: & $48 \%$ \\
Tweets with URLs: & $47 \%$ \\
Tweets with Mentions: & $27 \%$ \\
Tweets with Media (photos and videos): & $9 \%$ \\
\hline
\end{tabular}

\title{
8 Examining level of engagement
}

\author{
"How do we define success?" - Fire Service Interviewee
}

The online nature of social media means that it is difficult, if not impossible, to determine whether the actions on social media attribute to the real actions offline. Drawn from the responders interview responses, it is evident that the responders do not appear to know how to measure the success of their social media usage - they do not know how many people they are actually reaching in an emergency, and struggle to determine how helpful the information they share on social media is. Generally, the responders rely on monitoring the number of followers as an indication.

"As indicated by the number of followers the [service] have got, it's not really huge. . so you really need a greater number of followers"- Local Authority Interviewee

“In terms of numbers, it's a drop in the ocean really. . .but we've just got to keep plugging away to try and get more people to follow us" - Local Authority Interviewee

"There's no point tweeting to a few followers, you need thousands"-Ambulance Service Interviewee

Whilst the number of followers is objective, it does not actually explain much about social media success. Merely counting the number of followers can be misleading about 
the actual rates of engagement, as it provides an insight only into how many users will potentially see a message. It cannot be assumed that every follower will actually see every post (Phethean et al., 2012). However, metrics representing the possible reach and level of engagement can help to discover the potential impact of a user's social media activity (Phethean et al., 2012).

Constraints of the Twitter data available to access, meant that the number of followers for each Responder (included in the data sample) during the UK Floods 2013-2014 could not be obtained. However, the number of favourites and retweets received, which were acquired, can indicate a level of engagement (Zamparas et al., 2015).

As stated earlier, to favourite a tweet (i.e, the action of liking a tweet) indicates that a user wishes to show appreciation for that post (Kwak et al., 2010), and retweeting (i.e, reposting another user's tweet) suggests that a user deems that message worthy. Henceforth, the term level of engagement will denote the number of favourites and retweets received.

To determine if, and how, the responders' engage their audience on social media, the level of engagement during the UK Floods 2013/14 is examined here.

Figure 2 illustrates the percentage of the level of engagement each LRF attained, where the percentage is: the total number of favourites and retweets each LRF received divided by the total number of tweets each LRF posted. The percentages can be greater than 100 as one tweet can yield more than one interaction (favourite/retweet). As the graph shows, the level of engagement varied significantly by LRF; Hampshire and IoW LRF received the most interactions and Wiltshire and Swindon LRF received the fewest.

Figure 2 Level of engagement from audience across LRFs (see online version for colours)

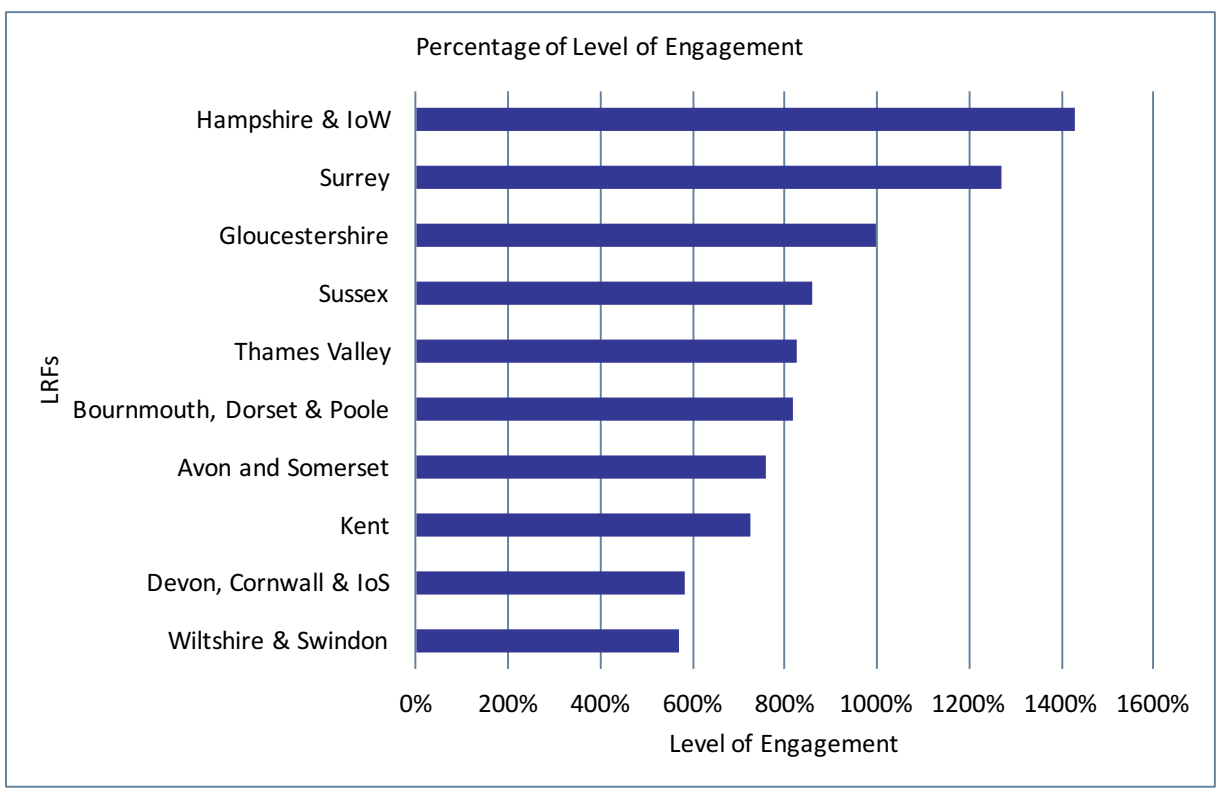

Many reasons could explain this variability across LRFs, such as: the population size covered by each LRF may vary; the number of followers for each LRF may differ significantly; and, some responders may have been using Twitter longer than others. However, from the 
interview responses, it was evident that the responders employ different strategies when using social media; they tend to take a content led or image led approach.

"We take a content led approach, which is if there's good content, and it's worth sharing on both channels [Twitter and Facebook], then we do that, because it gets great interaction" - Fire Service Interviewee

"In an incident we try to use it to give public information about evacuation, where they can go to tune in, whether we've got flood alerts or weather warnings, those kind of things." - Local Authority Interviewee

"Mostly at the moment we are just using image sharing" - Local Authority Interviewee

Therefore, this paper will concentrate on identifying the aspects of the responders' Twitter activity that impacted the level of engagement, i.e., determine factors of the responders' Twitter activity that may have enticed their audience to interact (such as retweet or favourite).

\section{Discussion}

Correlation and multiple regression analyses were conducted to examine the level of engagement. The first test focused on the content categories (Caution and Advice, Infrastructure and Utilities, Donation and Volunteer, Rescue, Sympathy and Support, Affected Individuals, Flood Related, and Other Information). Interestingly, the first test revealed that only the Infrastructure and Utilities category (posts about structures and utilities that have been affected by the incident) explained a proportion of the variance statistically $(63 \% ; p<0.05)$. The other categories did not have any association statistically. The Pearson's product-moment correlation coefficient $(0.795, p<0.05)$ indicates a large positive association between the level of engagement and the Infrastructures and Utilities category. The plot in Figure 3 shows that the LRFs that posted a large number of tweets categorised as Infrastructures and Utilities, achieved a higher level of engagement, indicating that during an emergency, tweets about Infrastructures and Utilities are more likely to engage the audience.

A second multiple regression model was fitted to investigate the following six variables: the number of tweets, level of interaction responders attempted (number of retweets, quote retweets and replies), number of tweets containing at least one hashtag, number of tweets containing at least one mention, number of tweets containing a URL, and number of tweets containing media (photos and videos). The results showed that the use of photos and videos explained $85 \%$ of the variation in the level of engagement $(p<0.01)$. The other variables do not explain the variance statistically. Furthermore, a large positive correlation was found between the variables $(0.920 ; p<0.01)$, illustrating that the LRFs that posted the highest proportion of photos and videos also obtained a higher level of engagement (Figure 4). Although this may be less surprising, during the UK Floods, only $9 \%$ of the tweets included a photo and video.

The obtained correlations taken together suggest that the responders can achieve a level of engagement on social media during an emergency. However, if they focus more on posting content related to the Infrastructure and Utilities category, and include more photos and videos, they are likely to achieve a much higher level of engagement. Although, measuring the number of retweets and favourites to represent the level of engagement does not imply 
absolute impact, it is only an indication; Users may favourite a post to show appreciation, or retweet a post they deem to be worthy to forward on to their followers, but it does not mean that they are following the responders every message, or retaining the information provided by the responders. Further research would be required, involving the responders' followers, to determine how effective the responders use of Twitter actually is during an emergency.

Figure 3 Correlation between percentage of tweets categorised as infrastructure and utilities and the level of engagement (see online version for colours)

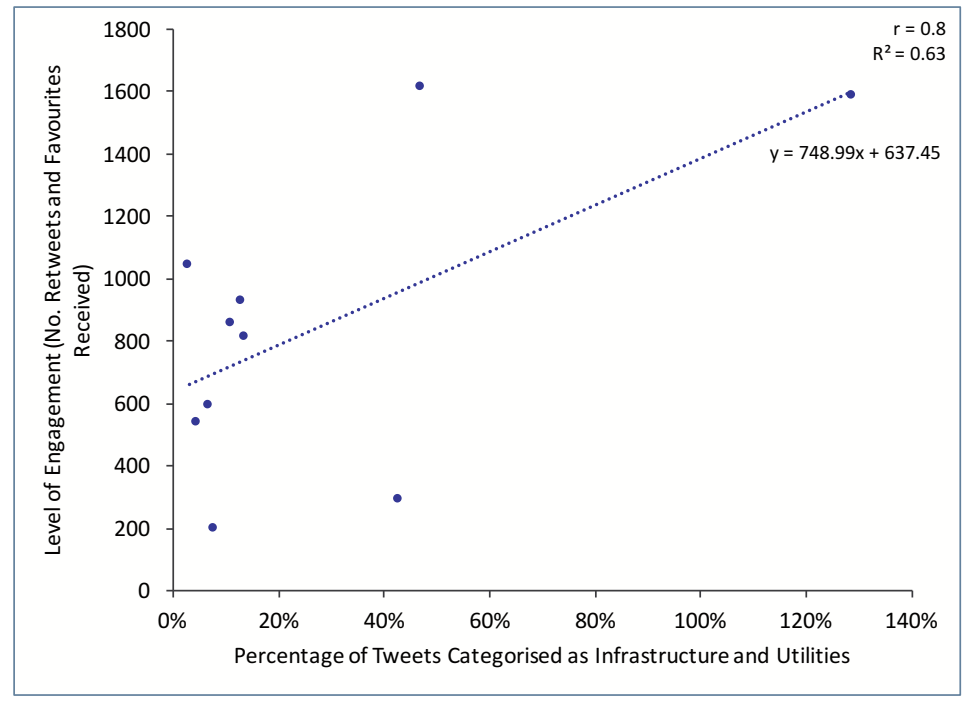

Figure 4 Correlation between percentage of tweets containing media and level of engagement from audience (see online version for colours)

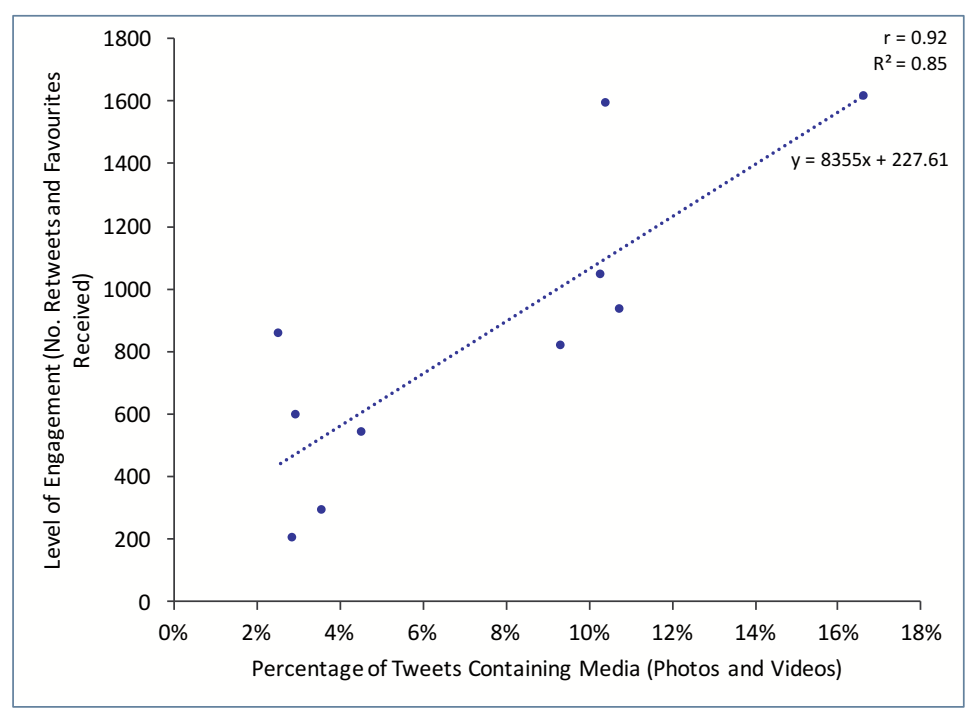


Despite this caution, what this research has shown is that whilst the use of social media as a tool to communicate with the public seems promising, it should not be the only tool used, and should not replace other traditional methods, for distributing emergency information. It should only be seen as a mechanism to supplement the responders communications toolkit. Here, only the number of favourites and retweets was analysed to represent the level of engagement. This provides only an indication of engagement, as currently there is little evidence to show who they are actually reaching and engaging. Furthermore, constraints of social media, including the design of the platforms, and the demography of the social media population, are but a few of the many factors that may hinder the success of reaching the desired audience during an emergency.

\section{Conclusion}

This research has investigated the perception, motivation and use of social media amongst UK emergency responders for emergency management, providing one of the first analyses of the role that social media now plays, and it's potential impact, in emergency management in the UK.

It is clear from this research that UK emergency responders believe that social media does play a role in emergency management. UK responders are turning to social media as a means to improve emergency communications, which has been one of the main causes of failures in past emergencies. They perceive it as a tool that will enable them to quickly and effectively deliver emergency information to the public, which has previously been one of the biggest challenges for the responders. During the UK Floods 2013-2014, the UK emergency responders used Twitter as a mechanism to distribute information related to the event, although some were more active than others. However, issues surrounding the availability of resources appear to hamper the responders' ability to exploit social media for information gathering purposes.

The results highlighted a difference between how the responders believe they are using social media, and how they appear to use social media. While they wished to use an engagement approach to increase the likeliness of reaching their audience, the Twitter analysis suggested otherwise; very few tweets were posted by each responder, they rarely participated in conversation with the Twitter community, and they hardly used features such as hashtags, URLs and photos and videos, all of which are believed to be effective methods for engaging an audience on Twitter. This is a key benefit for using a mixed methods approach. Significant findings such as this would have been impossible without the data that each method enables to be generated.

The evidence did show that a level of engagement was achieved, although it varied significantly by LRF. Using statistical tests to further investigate this variability, it was discovered that the responders could possibly increase the level of engagement on social media in future emergencies, if they post more information about structures, such as bridges and roads, and utilities, such as water and electricity supply, that are affected by the emergency (the Infrastructures and Utilities category), and include more photos and videos in their posts.

During the UK Floods, the responders appeared to predominantly post Caution and Advice related tweets, and hardly posted any media (only $9 \%$ of tweets contained a photo or video). Only the content category Infrastructures and Utilities explained a significant 
amount of the variance in the level of engagement. Furthermore, the variables: number of tweets, use of URLs and Hashtags, and use of mentions, were not found to have an effect.

Only the use of media had a large significant correlation with the level of engagement. Therefore, if emergency responders are going to continue pursuing the use of social media, and integrate it into emergency practice in an attempt to improve emergency communications, they should consider increasing the number of posts related to Infrastructure and Utilities content, as this appears to be of more interest to the audience, and increase the use of media.

Before it can be determined if social media is an effective tool for emergency management, and fulfils the role that emergency responders believe it can play in emergency management, further research is required to answer the questions that currently remain unanswered, such as: Who are the responders followers on social media? Are the responders actually reaching the public in emergency situations? Do the public find the responders social media activity useful in an emergency? What do the emergency responders actually gain by having a social media presence? Future research will sought to answer these pertinent questions.

\section{Acknowledgements}

This research was funded by the Research Councils UK Digital Economy Programme, Web Science Doctoral Training Centre, University of Southampton [EP/G036926/1]

\section{References}

Adam, A. and Muraki, Y. (2011) 'Twitter for crisis communication: lessons learned from Japan's tsunami disaster', International Journal of Web Based Communities, Vol. 7, No. 3, pp.392-402.

Alexa (2017) The Top 500 Sites on the Web, Available at: http://www.alexa.com/topsites/ category/Computers/Internet/On_the_Web/Online_Communities/Social_Networking

Anderson, I. (2002) Foot and Mouth Disease: Lessons to be Learned Inquiry Report, London. Available At: http://webarchive.nationalarchives.gov.uk/20100807034701/http:/archive.cabinet office.gov.uk/fmd/fmd_report/report/index.htm

Boyd, D., Golder, S. and Lotan, G. (2010) 'Tweet, Tweet, Retweet: conversational aspects of retweeting on Twitter', Hawaii International Conference on System Sciences, Kauai.

Braun, V. and Clarke, V. (2006) 'Using thematic analysis in psychology', Qualitative Research in Psychology, Vol. 3, No. 3, pp.77-101.

Briones, R.L., Kuch, B., Liu, B.F. and Jin, Y. (2011) 'Keeping up with the digital age: How the American Red Cross uses social media to build relationships', Public relations review Vol. 37, No. 1, pp.37-43.

Bruns, A., and Stieglitz, S. (2013) 'Towards more systematic Twitter analysis: metrics for tweeting activities', International Journal of Social Research Methodology, Vol. 16, No. 2, pp.91-108.

Bryman, A. (2012) Social Research Methods, 4th ed., Oxford University Press, Oxford.

Cabinet Office. (2013) Expectations and Indicators of Good Practice Set for Category 1 and 2 responders Contents. Assembly, London, Available at: https://www.gov.uk/ government/uploads/system/uploads/attachment_data/file/252341/Expectation_and_ Indicators_of_Good_Practice_Set_for_category_1_2_responders.pdf 
Cabinet Office. (2014) Preparation and Planning Emergencies: the National Resilience Capabilities Programme, Available At: https://www.gov.uk/preparation-and-planning-for-emergencies-thecapabilities-programme

Cha, M., Haddadi, H., Benevenuto, F. and Gummadi, K. (2010) 'Measuring user influence in Github: the million follower fallacy', Proceedings of the Fourth International AAAI Conference on Weblogs and Social Media, Vol.10, No.30, pp.10-17.

Chu, Z., Gianvecchio, S., Wang, H. and Jajodia, S. (2010) 'Who is Tweeting on Twitter: Human, Bot, or Cyborg?', Acsac. 2010.

Civil Contingencies Act, (2004), c.36.

Creswell, J. and Plano, V. (2007) Designing and Conducting Mixed Methods Research, 2nd ed., SAGE, London.

Curtis, S, (2013) Twitter Claims 15M Users in the UK, The Telegraph, Available at: http://www. telegraph.co.uk/technology/twitter/10291360/Twitter-claims-15m-active-users-in-the-UK.html

DEFRA. (2014) The National Flood Emergency Framework for England, London, Available at: https://www.gov.uk/government/uploads/system/uploads/attachment_data/file/388997/pb1 4238-nfef-201412.pdf

Dufty, N. and Stewart, M. (2016) 'AJEM Twitter turns ten: its use to date in disaster management', Australian Journal of Emergency Management, Vol. 31, No. 2, pp.50-54.

HM Government. (2013) Emergency Response and Recovery Non Statutory Guidance Accompanying the Civil Contingencies Act 2004, Available from: https://www.gov.uk/ government/uploads/system/uploads/attachment_data/file/253488/Emergency_Response_ and_Recovery_5th_edition_October_2013.pdf

Hughes, A.L., Palen, L., Sutton, J., Liu, S.B. and Vieweg, S. (2008) "Site-Seeing" in disaster: an examination of on-line social convergence', Proceedings of the 5th International ISCRAM Conference - Washington, DC, USA, pp.324-333. Information Systems for Crisis Response and Management, ISCRAM.

Hughes, A.L., Denis, L., Palen, L. and Anderson, K.M. (2014) 'Online public communications by Police \& Fire services During the 2012 Hurricane Sandy', Proceedings of the 32nd Annual ACM Conference on Human Factors in Computing Systems - CHI '14, pp.1505-1514.

Kaplan, A.M. and Haenlein, M. (2010) 'Users of the world, unite! the challenges and opportunities of social media', Business Horizons, Vol. 53, No. 1, pp.59-68.

Kwak, H., Lee, C., Park, H. and Moon, S. (2010) 'What is Twitter, a social network or a news media? categories and subject Descriptors', 19th International Conference on World Wide Web, pp.591-600.

Lewis-Beck, M.S. Bryman, A. and Liao. T.F (2004) Encyclopedia of Social Science Research Methods, SAGE Publications.

Mei, Y., Zhong, Y. and Yang, J. (2015) 'Finding and analyzing principal features for measuring user influence on Twitter', 2015 IEEE First International Conference on Big Data Computing Service and Applications, pp.478-486.

Met Office (2015a) Winter storms, January to February 2014, Available at: http://www.metoffice. gov.uk/climate/uk/interesting/2014-janwind

Met Office (2015b) Winter 2013/14, Available at: http://www.metoffice.gov.uk/climate/uk/ summaries/2014/winter

Office for National Statistics (2013) Social Networking: The UK as a Leader in Europe, Available at: http://webarchive.nationalarchives.gov.uk/20160105160709/http://www.ons.gov.uk/ons/rel/ rdit2/internet-access-households-and-individuals/social-networking-the-uk-as-a-leader-ineurope/sty-social-networking-2012.html

Office for National Statistics (2016) United Kingdom Population Mid Year Estimate, Available at: https://www.ons.gov.uk/peoplepopulationandcommunity/populationandmigration/populationes timates/timeseries/ukpop/pop 
Olteanu, A., Vieweg, S. and Castillo, C. (2015) 'What to expect When the unexpected happens': social media communications across crises', Computer-Supported Cooperative Work and Social Computing CSCW'15, Vancouver.

Palen, L., Starbird, K., Vieweg, S. and Hughes, A. (2010) 'Twitter-based information distribution during the 2009 red river Valley Flood threat', Bulletin of the American Society for Information Science and Technology, Vol. 36, No. 5, pp.13-17.

Parsons, S., Atkinson, P.M., Simperl, E. and Weal, M. (2015) 'Thematically analysing social network content during disasters through the lens of the disaster management lifecycle', In SWDM'15 in World Wide Web Conference.

Phethean, C., Tiropanis, T. and Harris, L. (2012) 'Measuring the performance of social media marketing in the charitable domain', WebSci 2012.

Phethean, C. (2014) Exploring the Value of Social Media Services for Charitable organisations: A Mixed Methods Approach, (Doctoral dissertation, University of Southampton).

Pitt, M. (2008) 'Learning lessons from the 2007 floods', The Pitt Review, London, Available at: http://webarchive.nationalarchives.gov.uk/20100807034701/http:/archive.cabinetoffice.gov.uk/ pittreview/_/media/assets/www.cabinetoffice.gov.uk/flooding_review/pitt_review_full\% 20pdf.pdf

Pollock, K. (2013) Review of Persistent Lessons Identified Relating to Interoperability from Emergencies and Major Incidents since 1986, Vol. 6, Available at: http://www.jesip.org.uk/ uploads/media/pdf/Pollock_Review_Oct_2013.pdf

Rogers, L. and Bryson, M. (2014) '10 key moments of the UK winter storms', BBC News, Available at: http://www.bbc.co.uk/news/uk-26170904

Ryan, G. W. and Bernard, H. R. (2003) 'Techniques to Identify Themes', Field Methods, Vol. 15, No. 1, pp.85-109.

Salonga, S. (n.d) 'verbatim vs. intelligent vs. edited transcription', Globalme, Available At: https://www.globalme.net/blog/verbatim-vs-intelligent-vs-edited-transcription.

Simon, T., Goldberg, A. and Adini, B. (2015) 'Socializing in emergencies-A review of the use of social media in emergency situations', International Journal of Information Management, Vol. 35, No. 5, pp.609-619.

Siskey, A. and Islam, T. (2016) 'Social media best practices in emergency management', J. Emerg. Manag., Vol. 14, No. 2, pp.113-125.

Slingo, J., Belcher, S., Scaife, A., McCarthy, M., Saulter, A., McBeath, K., Jenkins, A., Huntingford, C., Marsh, T., Hannaford, J. and Parry, S. (2014) The Recent Storms and Floods in the UK. Devon, Available at: http://www.metoffice.gov.uk/media/pdf/n/i/Recent Storms_Briefing_Final_07023.pdf

SPEECHPAD (2016) Types of Transcription, Available at: https://blog.speechpad.com/types-oftranscription/

Strom, K.J. and Eyerman, J. (2008) Interagency Coordination: Lessons Learned From the 2005 London Train Bombings, National Institute of Justice, Vol. 261. Available at: https://www.ncjrs.gov/ pdffiles1/nij/224088.pdf

Suh, B., Hong, L., Pirolli, P. and Chi, E.H. (2010) 'Want to be retweeted? large scale analytics on factors impacting retweet in twitter network', Proceedings - SocialCom 2010: 2nd IEEE International Conference on Social Computing, PASSAT 2010: 2nd IEEE International Conference on Privacy, Security, Risk and Trust, pp.177-184.

Terpstra, T., Stronkman, R., De Vries, A. and Paradies, G.L. (2012) 'Towards a realtime Twitter analysis during crises for operational crisis management', Proceedings of 9th International ISCRAM Conference - Vancouver, Canada 2012, pp.1-9.

Thorne, C. (2014) 'Geographies of UK flooding in 2013/4', Geographical Journal, Vol. 180, No. 4, pp.297-309. 
Vieweg, S., Palen, L., Liu, S.B., Hughes, A.L. and Sutton, J. (2008) 'Collective intelligence in disaster: examination of the phenomenon in the aftermath of the 2007 Virginia tech shooting', Proceedings of the Information Systems for Crisis Response and Management (ISCRAM)(May), pp.44-54.

Vieweg, S., Hughes, A.L., Starbird, K. and Palen, L. (2010) 'Microblogging during two natural hazards events: What Twitter may contribute to situational awareness', CHI 2010: Crisis Informatics, pp.1079-1088.

White, C.M. (2011) Social Media, Crisis Communication, and Emergency Management: Leveraging Web 2.0 Technologies, CRC press.

Wood, M. and Glik, D. (2013) Engaging Californians in a shared vision for Resiliency - Practical Lessons Learned from the Great California Shakeout, Los Angeles.

Wukich, C., and Mergel, I. (2015) 'Closing the citizen-government communication gap: content, audience, and network analysis of government tweets', Journal of Homeland Security and Emergency Management, Vol. 12, No. 3, pp.707-735.

Yetim, F., Wiedenhoefer, T. and Rohde, M. (2011) 'Designing for motivation: Focusing on motivational values in two case studies', Third International Conference, SocInfo 2011, Vol. 6984 LNCS. Springer, Singapore.

Zamparas, V., Kanavos, A. and Makris, C. (2015) 'Real time analytics for measuring user influence on Twitter', 2015 IEEE 27th International Conference on Tools with Artificial Intelligence (ICTAI), pp.591-597.

\section{Note}

${ }^{1}$ https://www.gov.uk/government/uploads/system/uploads/attachment_data/file/85946/Usingsocial-media-in-emergencies-smart-tips.pdf 